\title{
A INFLUÊNCIA DO PORTO DIGITAL NA REPRESENTAÇÃO DO DESENVOLVIMENTO DE PERNAMBUCO
}

\author{
Anderson Diego Farias da Silva ${ }^{1}$ \\ Nelson da Cruz Monteiro Fernandes ${ }^{2}$ \\ Fernando Gomes de Paiva Júnior ${ }^{3}$
}

\begin{abstract}
RESUMO
Este estudo tem por objetivo compreender a influência do Arranjo Produtivo Local de Tecnologia da Informação e Comunicação (APL de TIC), denominado Porto Digital, localizado na Cidade Metropolitana do Recife, na representação do desenvolvimento do Estado de Pernambuco. Foi realizada uma pesquisa qualitativa, por meio da análise dos dados obtidos através de pesquisa documental e da realização de entrevistas semiestruturadas. Os resultados evidenciam que a representatividade do Porto Digital em relação ao desenvolvimento de Pernambuco, se estabelece por meio da identidade, do patrimônio e da Pernambucanidade. O que possibilita a geração de novas alternativas em relação as cadeias produtivas do Estado, bem como a permanência dos talentos e a expansão dos centros de pesquisas e universidades.
\end{abstract}

PALAVRAS-CHAVE: REPRESENTAÇÃO. CIRCUITO DA CULTURA. ARRANJO PRODUTIVO LOCAL. PORTO DIGITAL.

\footnotetext{
${ }^{1}$ Mestrando em Administração (UFPE). Especialista em Administração de Marketing (UPE-FCAP). Graduado em Administração (FACOL). Tutor UAEADTec, Professor Estagiário (UFPE).

${ }^{2}$ Doutor em Administração (UFPE). Mestre em Sociologia (UFPE). Graduado em Administração (Universidade Católica de Pernambuco - UNICAP). Professor da UFPE.

${ }^{3}$ Doutor em Administração (UFMG). Mestre em Administração (Universidad de Deusto, País Basco, Espanha). Graduado em Administração (UFPE). Professor adjunto IV (UFPE).
} 


\section{INTRODUÇÃO}

O intenso processo de reestruturação produtiva que vem ocorrendo na economia global e as profundas transformações tecnológicas, que sob a ótica desse processo, vêm atingindo o mundo do trabalho desde o início dos anos 80 , têm incentivado o desenvolvimento de pesquisas que busquem compreender as profundas modificações provocadas por esse processo, especialmente debruçadas sobre suas várias manifestações, transformações e implicações para a sociedade (HARVEY, 2012; JULIEN, 2010; CASTELLS, 2007; LEE, 1993).

Entretanto, não somente na esfera econômica encontramos os reflexos da globalização, a considerar que também é possível destacar a concepção da "sociedade do conhecimento" no âmbito da transposição dos valores materialistas para os valores pós-materialistas. $\mathrm{Na}$ esfera cultural passam a existir as comunidades de afinidades, que são os locais onde as necessidades individuais emergem e há o desprendimento da dimensão coletiva, ocasionando mudanças no modo de consumo (YÚDICE, 2006; JOHANNESSEN e OLSEN, 2010). Esses novos contextos econômicos, sociais e culturais potencializam e evidenciam a produção de bens simbólicos.

A partir das mudanças nos padrões de consumo e nos valores culturais emergiram novas expectativas e ensejos em torno do papel dos bens tecnológicos na vida das pessoas. Diversas empresas de grande porte - como Apple e Nokia criaram novas posições estratégicas em seus respectivos mercados, adaptando a aparência e o sentimento de seus produtos convencionais, possibilitando aos seus consumidores a mudança na forma como eles experienciam e as associações que eles evocam sobre os produtos (RAVASI e LOJACOMO, 2005). Portanto, "para os consumidores, as mercadorias são símbolos, cuja posse e uso refletem, expressam e reconstituem o sistema de relacionamento social e seu lugar percebido" (RAVASI e RINDOVA, 2008, p. 270).

Em Pernambuco, constituiu-se por meio do Arranjo Produtivo Local (APL) de Tecnologia de Informação e Comunicação (TIC), denominado Porto Digital, uma 
rede colaborativa complexa, onde os agentes empreendedores se articulam com outros, interagem com seu ambiente e buscam produzir bens simbólicos.

Em 13 anos de atuação, o Porto Digital vem se consolidando como um dos principais APL do Brasil, sendo inclusive, reconhecido internacionalmente. Nesse sentido, o objetivo do presente estudo é buscar compreender, por meio da realização de uma pesquisa qualitativa, como o Porto Digital se tornou uma representação do desenvolvimento de Pernambuco?

\section{FUNDAMENTAÇÃO TEÓRICA}

Nas seções a seguir, veremos o período de reestruturação do capitalismo, por meio da transição do modelo industrial para o modelo pós-industrial, bem como o surgimento de novas práticas e modelos organizacionais, como os Arranjos Produtivos Locais (APL's), e o que isso reverbera no surgimento de novas vivências sociais, culturais e econômicas.

\section{1 [Re]estruturação do Capitalismo: Transição do Modelo Industrial para o Pós-industrial}

Durante boa parte do século $X X$, o modo de produção que caracterizava a racionalização capitalista era a fusão do taylorismo e do fordismo, definido como a produção eficiente de uma coisa, utilizando mão-de-obra especializada. A data inicial simbólica do fordismo deve por certo ser 1914, quando Henry Ford introduziu seu dia de oito horas e cinco dólares como recompensa para os trabalhadores da linha automática de montagem (HARVEY, 2012, p. 121).

Em muitos aspectos, as inovações organizacionais e tecnológicas de Ford eram mera extensão de tendências consolidadas. A forma corporativa de organização de negócios, por exemplo, tinha sido aperfeiçoada pelas estradas de ferro ao longo do século XIX e os Princípios da Administração Científica, de F. W. 
Taylor (1995) - um influente tratado que descrevia como a produtividade do trabalho podia ser radicalmente aumentada através da decomposição de cada processo de trabalho em movimentos componentes e da organização de tarefas de trabalho fragmentadas segundo padrões rigorosos de tempo e estudo do movimento —, tinham sido publicados (HARVEY, 2012, p. 121). A tecnologia de linha de montagem para produção de massa, implantada em muitos pontos dos Estados Unidos, tinha um desenvolvimento muito fraco na Europa antes da metade dos anos 30 (HARVEY, 2012, p. 124). Depois de 1945 o fordismo chegou à maturidade como regime de acumulação plenamente acabado e distintivo.

Como tal, ele veio a formar a base de um longo período de expansão pósguerra que se manteve mais ou menos intacto até 1973. Ao longo desse período, a economia nos países capitalistas avançados alcançou taxas fortes, mas relativamente estáveis de crescimento, as tendências de crise foram contidas, a democracia de massa preservada e a ameaça de guerras intercapitalistas, tornada remota: o fordismo se aliou firmemente ao keynesianismo, e o capitalismo se dedicou a um surto de expansões internacionalista de alcance mundial que atraiu para a sua rede inúmeras nações descolonizadas (HARVEY, 2012, p. 125).

Só quando a aguda recessão de $1973^{4}$ abalou esse quadro, um processo de transição rápido, mas que segundo Harvey (2012, p. 134) ainda não bem entendido, do regime de acumulação teve início.

Mas a complexidade histórica dessa transição ou a falta de consenso sobre as reais causas e consequências desse período têm trazido alguns desafios para as Ciências Sociais, que tem produzido uma miríade de interpretações para compreender essa nova ordem. Smith (1994) caracterizou essa transição como uma parcial modificação do sistema de produção no sentido de uma ampliação da diversidade de produtos, mas substancialmente dentro do mesmo marco de estreito

4 Que entre as causas mais frequentemente apontadas estariam a decisão da OPEP de aumentar os preços do petróleo e a decisão árabe de embargar as exportações de petróleo para o ocidente durante a guerra árabe-israelense de 1973 aliadas a produtividade decrescente por causa do aumento da alienação, falência do Estado de Bem-Estar Social e resistência do trabalhador (KUMAR, 1997, p. 68). 


\section{VIANNA SAPIENS}

controle patronal, de especialização e mecanização. Cauteloso também, Harvey (2012) indaga se essas mudanças assinalaram o nascimento de um novo regime de produção capaz de conter as contradições do capitalismo durante a próxima geração ou se marcam uma série de reparos temporários, constituindo assim um momento transacional de dolorosa crise na configuração do capitalismo do final do século XX. Talvez por isso que Kumar (1997, p. 72) afirma que o que está sendo saudado como "pós-fordismo" seja apenas a mais recente roupagem tecnológica e organizacional do fordismo.

Segundo Coriat, (1985 p. 35) esse novo paradigma, o pós-fordismo, conservaria os princípios do fordismo, como a disciplina essencial na cadeia de montagem, nos postos e tarefas rotineiras, mas introduziu outros elementos como a segmentação das cadeias em espaços distintos, cada um abastecido por sua própria reserva de componentes e ferramentas e a introdução do trabalho em equipe e em grupo, em vez do principio fordista de um homem/um posto/um emprego (CORIAT, 1980 p. 35-36). Nisso surge Manuel Castells (2007, p. 305) com uma idéia fundamental: a automação, que só se completou com a tecnologia de informação, aumenta enormemente a importância dos recursos do cérebro humano no processo de trabalho. Então podemos supor que a autonomia perdida na transição da produção artesanal para a produção em massa se recupera em um novo contexto tecnológico e de produção.

Assim, abriu-se o caminho para a chamada fase da produção flexível que entra em conflito com a rigidez da burocracia e os males da rotina cega (SENNETT, 1999, p. 9) do fordismo. A flexibilização do mercado e das relações de trabalho surgiu na mesma onda neoliberal que trouxe à tona questões como a desregulamentação da economia e a privatização. O objetivo é restaurar a hegemonia do mercado e facilitar a inserção da economia em novos padrões competitivos, tanto a nível doméstico quanto internacional. 
Hoje, entretanto, do sistema de produção industrial, passou-se ao sistema de produção informacionalizada ${ }^{5}$ caracterizada pela produção de informação, imagens e serviços. O nascimento da informação não só como conceito, mas também como ideologia, está inextricavelmente ligado ao desenvolvimento do computador durante os anos de guerra e no período imediatamente posterior. A transformação tecnológica e administrativa do trabalho e das relações produtivas dentro e em torno da empresa emergente em rede é o principal instrumento por meio do qual o paradigma informacional e o processo de globalização afetam a sociedade em geral. A produtividade e a competitividade dos agentes nessa economia dependem de sua capacidade para gerar, processar e aplicar de forma eficiente informação baseada em conhecimentos (CASTELLS, 2007, p. 119). E para consolidar esse cenário Kumar (2007) diz que o trabalho e o capital, as "variáveis" básicas da sociedade industrial, são substituídas por informação e conhecimento.

Segundo Castells (2007), a difusão das tecnologias de informação ${ }^{6}$ no processo produtivo levaria à adoção de novas práticas organizacionais, com o objetivo de reestruturar os processos de trabalho, as práticas de emprego e oferecendo supostamente ao trabalhador maior capacidade de intervir nos processos decisórios. Assim já não haverá uma prescrição total.

Diante destas condições, as organizações tradicionais estão sendo demolidas, as empresas se integram e se descaracterizam, passando a formar redes, cadeias, conglomerados e alianças estratégicas, as denominadas organizações pós-fordistas (CLEGG e HARDY, 1999). A emergência desse novo formato, a empresa em rede, surge como resposta adaptativa às demandas por individualização da mão-de-obra, agilidade, flexibilidade, mobilidade, capacidade de gerar conhecimento e processar informações com eficiência para atender as

5 Global e em rede, acrescentaria Castells (2007, p.119)

6 As TICs fornecem a base técnica para os novos modos de reprodução e valorização do capital, seja o capital financeiro, transformado em pura informação, seja o capital produtivo, ao permitirem a flexibilização do aparato técnico e do trabalho e ao viabilizarem a produção e a circulação de um conjunto de bens informacionais de ágil produção, comercialização e consumo. (Albagli e Maciel, 2005). 
necessidades crescentes de lucro do capital. A morfologia da rede parece estar bem adaptada a crescente complexidade de interação e aos modelos imprevisíveis do desenvolvimento derivado do poder criativo dessa interação (CASTELLS, 2007, p.108).

Tais aspectos, consequentemente, acarretam novas vivências sociais, culturais e emocionais para todos os indivíduos de modo geral, bem como novas experiências para o trabalhador obrigado a uma abertura ao novo, configurado nas diversas tecnologias e paradigmas.

\subsection{A Representação segundo Hall (1997)}

A Representação é uma das práticas centrais que produzem cultura e momento chave do circuito da cultura (figura 01).

Figura 1: O Circuito da Cultura de Du Gay et al

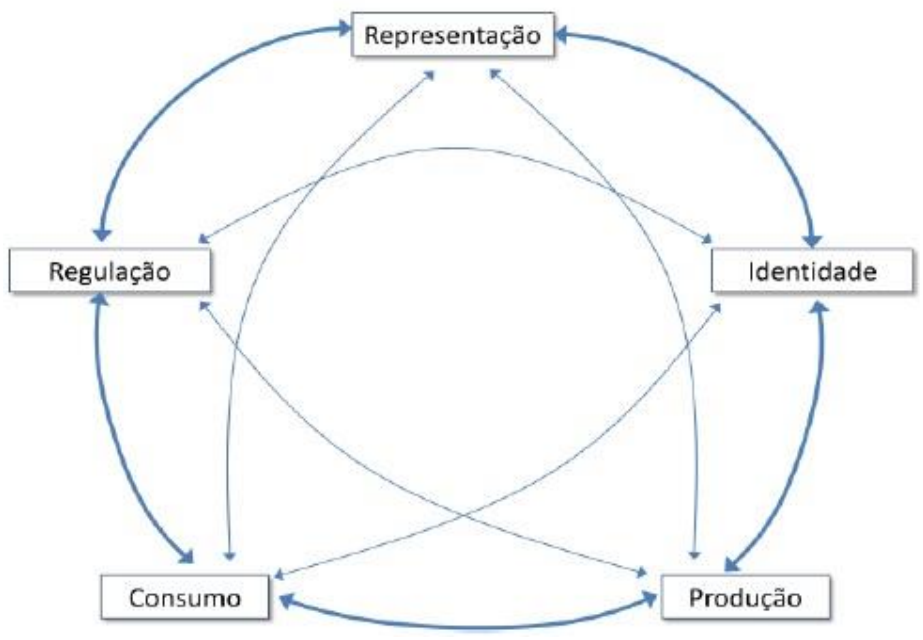

Fonte: Du Gay et al. (1997a, p. 3).

Mas, ao verificarmos a relação que à representação teria com a cultura, logo, percebemos que a Cultura tem a ver com significados compartilhados. Nesse sentido, a Linguagem é o meio privilegiado em que damos sentido às coisas, em que o significado é produzido e partilhado. Onde, os significados só podem ser 
Revista das Faculdades Integradas Vianna Júnior

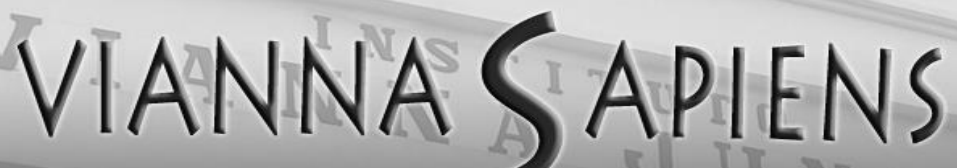

edição especial

compartilhados através do nosso acesso comum à linguagem. Assim, a linguagem é central ao significado e à cultura, e sempre foi considerado como repositório central de valores culturais e significados (HALL, 1997).

Representação para Stuart Hall (1997) é a produção do significado, do conceito em nossas mentes através da linguagem, muito adiante da existência de fato ou da observação empírica. O elo entre conceito e linguagem nos permite fazer referência tanto ao mundo "real" de objetos, pessoas ou eventos, assim como ao mundo ficcional destes (Idem, p. 17). Existem dois sistemas de representação. Há o sistema de correlação e o de Linguagem. O sistema de correlação é o que os objetos, pessoas e eventos são correlacionados com um conjunto de conceitos ou representações mentais que fazemos em nossas mentes. Já o de Linguagem possibilita a existência de um mapa conceitual compartilhado, através do qual possamos representar ou intercambiar significados ou conceitos.

Há, portanto, conforme Hall (1997) um processo mental e de tradução para o sistema em que fomos ensinados a referir o mundo, as pessoas e os eventos - é a construção de signos. Estes signos significam ou representam os conceitos e as relações conceituais entre estes que levamos em nossas mentes e que juntos compõem os sistemas de significação de nossa cultura.

Segundo Hall (1997) o significado não está no objeto, nem na pessoa, nem na coisa, nem mesmo na palavra. Somos nós que estabelecemos o significado de forma tão determinada que, em seguida, ele vem parecer natural ou inevitável. Sob essa lógica, o significado acontece em função de convenções associadas à linguagem que, por sua vez, funcionam como sistema de codificação do mundo, reconhecido e aceito comunitariamente por cada cultura segundo suas especificidades, ou seja, o significado é produzido pela prática, pelo trabalho da representação.

Uma representação fundamental para a apresentação do discurso do desenvolvimento econômico do Estado de Pernambuco, por meio do Porto Digital, é o reconhecimento de que Pernambuco possui as condições necessárias para a consolidação deste setor (CORREIA, 2007). Para esta autora uma representação 
simbólica, com capacidade aglutinadora, foi introduzida no discurso pelos elementos de identificação cultural vinculado ao Projeto, que significou este espaço como possibilidade de recuperação da posição perdida - e com ele a autoestima - do Estado que já foi expoente da região e perdeu, paulatinamente, a posição para outros estados nordestinos. A principal conclusão dessa reflexão é que o significado não é inerente às coisas do mundo. Ele é construído, produzido: é o resultado de uma prática de significações, que faz as coisas significarem.

A análise das informações institucionais do Porto Digital mostrou que existem elementos da identidade cultural local presentes nos textos divulgados no site do Porto Digital ${ }^{7}$. Assim, a utilização destes elementos de identidade cultural para a aderência ao discurso do desenvolvimento local via Porto Digital, constitui-se não apenas num fator de diferenciação, mas, principalmente, em um fator de autoestima. A ocupação de um bairro com edificações históricas numa região portuária onde se encontra o Marco Zero da cidade constitui fator importante para a materialidade do discurso que se pretende articular (CORREIA, 2007). Isso se alinha a proposta de Hall (1999) quando aponta que a identidade não nasce com o indivíduo, ela é formada e transformada no interior da representação que reflete um conjunto de significados de cada cultura.

Nesse sentido, três abordagens são usadas para representar o mundo. A reflexiva, intencional e construcionista. Na primeira a linguagem funciona como um espelho que reflete os significados já existentes no mundo (Objetos, pessoas e eventos) e a segunda reflete a imposição do significado do falante através da linguagem. A abordagem construtivista, que é a adotada nesse estudo, reflete a linguagem tomada como um produto social onde os significados são construídos através dos sistemas de representação.

A abordagem construtivista é uma reflexão que desestabiliza noções consolidadas pela própria cultura e que desafia o pesquisador a aprofundar sua análise, se estiver propondo-se a trabalhar com o sentido, numa busca de algo complexo e em permanente mutação. Assim, a profunda ligação entre os textos e as

\footnotetext{
${ }^{7}$ http://www.portodigital.org.br/
} 


\section{VIANNASAPIENS}

interações sociais, com as quais se relacionam como produtos e produtores, conferem aos significados veiculados nestes textos uma estabilidade apenas momentânea: os signos que constroem os mundos representados, o contexto das atividades humanas, estão sujeitos a constantes ressignificações introduzidas por mudanças passíveis de acontecer naquelas designações negociadas.

Para efeitos de nosso estudo as categorias abaixo indicadas, serão utilizadas para entendermos como ocorre o Porto Digital tornou-se um elemento da representação do desenvolvimento do Estado de Pernambuco.

Tabela 1: Categorias de Análise

\begin{tabular}{|c|c|}
\hline \multicolumn{2}{|l|}{ REPRESENTAÇÃO } \\
\hline CATEGORIAS & EVIDÊNCIAS \\
\hline IDENTIDADE: & $\begin{array}{l}\text { - "A identidade não é transparente ou problemática como } \\
\text { pensamos. Talvez, em vez de pensar a identidade como } \\
\text { um fato histórico já realizado... devemos pensar, em vez } \\
\text { de identidade como uma "produção", que nunca está } \\
\text { completa, sempre em processo, que sempre se } \\
\text { constituiu dentro, e não fora da representação" (HALL, } \\
\text { 1989). (tradução própria, 2013). }\end{array}$ \\
\hline PATRIMÔNIO: & $\begin{array}{l}\text { - Patrimônio é um conceito completamente moderno... } \\
\text { Nós construímos patrimônio, porque temos uma } \\
\text { necessidade cultural de fazê-lo em nossa era moderna. } \\
\text { Patrimônio é uma condição de finais do século XX... O } \\
\text { extraordinário fenômeno por meio do qual o passado é } \\
\text { aberto não só para a reconstrução, mas invenção. } \\
\text { (McCRONE, 1995). (tradução própria, 2013). }\end{array}$ \\
\hline $\begin{array}{l}\text { PERNAMBUCANIDADE } \\
\text { (Nacionalismo) }\end{array}$ & $\begin{array}{l}\text { - Os argumentos antropológicos postulam que cada } \\
\text { cultura dá sentido ao classificar as coisas. Classificação } \\
\text { significa enfatizar a diferença, o que significa que } \\
\text { quando você classifica algo há um princípio segundo o } \\
\text { qual você decidir o que é diferente ou similar - por isso } \\
\text { tem ir para esta classe de coisas. A idéia aqui é que a } \\
\text { diferença é criada por esses princípios de classificações } \\
\text { (aquelas coisas que você destaca como central para a }\end{array}$ \\
\hline
\end{tabular}




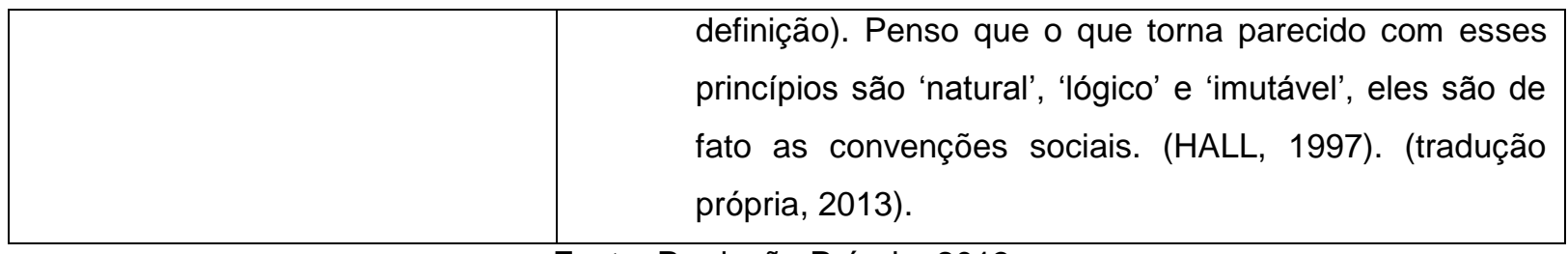

Fonte: Produção Própria, 2013.

\subsection{Os Arranjos Produtivos Locais (APLs)}

Os primeiros estudos referentes às aglomerações de empresas foram publicados por Alfred Marshall, em seu livro intitulado por "Princípios de Economia", na década de 1920. Em suas pesquisas, Marshall se interessava, em geral, sobre a localização das indústrias, geralmente relacionadas a condicionantes geográficos, físicos, climáticos, fatores de solo e do mercado consumidor (MARSHALL, 2006).

A partir das primeiras observações apresentadas por Marshall, percebeu-se que oportunidades e ganhos coletivos poderiam ser gerados através de atividades geograficamente agrupadas. Além disso, essa concentração espacial permitiria o desenvolvimento econômico e a geração de competitividade das empresas e regiões que não poderiam ser adquiridos no formato tradicional (isolado) dos negócios.

O termo "APL" foi criado por uma comissão interministerial do governo brasileiro no ano de 2004, buscando desenvolver políticas públicas direcionadas as aglomerações de empresas (NORONHA e TURCHI, 2005). Essa ação centrada nos APLs estimula o desenvolvimento regional, incentiva os vínculos verticais e horizontais entre as empresas e atores envolvidos (BERBEL, 2008).

Estudos mais recentes, conforme Kirschbaum et al. (2009, p. 186), definem os APLs como "aglomerações territoriais de agentes econômicos, políticos e sociais, com foco num conjunto específico de atividades econômicas". Cassiolato e Lastres (2003), corroboram afirmando que esses Arranjos são constituídos, em geral, pela participação e interação entre empresas, clientes, representações, instituições públicas e privadas. 
Os Arranjos Produtivos Locais estão inseridos em territórios por meio de condições específicas, sejam elas de ordem política, social, cultural, econômica e físico-espacial, do qual influenciam no seu desempenho e funcionamento.

Para Kirschbaum et al. (2009, p. 186):

Territórios são espaços delimitados por e a partir de relações de poder, campos de força, teias ou redes de relações sociais, demarcadores das diferenças entre os membros da coletividade e os de fora. São suportes materiais da existência e, simultaneamente, catalisadores de elementos simbólicos, podendo abranger escalas local, regional, nacional e mundial. O conceito de território supera a noção de espaço reduzida a distância, que gera custos de produção e de distribuição maiores ou menores, a depender das distâncias dos mercados de fatores de produção e de consumo.

Observa-se ao longo dos últimos anos uma proliferação de estudos acerca dos APLs, especialmente, no campo da produção e operação dos bens simbólicoculturais. O Porto Digital, APL de TIC e Economia criativa, localizado em Recife, emerge como um importante exemplo do que seria um APL no campo da produção simbólica (PORTO DIGITAL, 2012), ou seja, um sistema de relações intra e interempresas e instituições, englobando aglomerações territoriais de agentes econômicos, políticos, sociais e culturais.

\section{PROCEDIMENTOS METODOLÓGICOS}

A pesquisa qualitativa tem conseguido desmistificar a sofisticação estatística como o único caminho para se conseguir resultados significativos. Dentro das perspectivas que lidam com a interpretação das realidades sociais há um crescente uso da Análise do Discurso no tratamento das novas questões de pesquisa e na reformulação das antigas. E considerando-se a complexidade e pluralidade de discursos que podem percorrer qualquer coletividade, a Análise do Discurso possibilita explorar não só as ambiguidades e contradições, mas também os vários modos de representações, os múltiplos valores e a construção das significações da 
vida social pelos atores envolvidos. A forma como a língua é produzida e interpretada em um dado contexto é o foco da análise do discurso.

Gill (2002) ressalta que as origens da análise de discurso a partir de críticas a ciência social tradicional significa que ela possui uma base epistemológica bastante diversa de algumas outras metodologias, o que é às vezes chamada de construcionismo social, construtivismo ou simplesmente construcionismo. Maingueneau (1993) defende que a analise do discurso supõe um sentido oculto que deve ser captado, o qual, sem uma técnica apropriada, permanece inacessível. Interessante notar que não há procedimento fixo para se fazer análise de discurso, as pessoas abordam-na de diferentes maneiras, de acordo com a natureza especifica do projeto e conforme suas respectivas visões do discurso (FAIRCLOUGH, 2001). A identificação e a análise de discursos são muito influenciadas pelas formulações de Foucault (1997) em sua distinção entre discurso como um espaço geral de todas as afirmações, discurso como um grupo individualizado de afirmações, e discurso como uma prática regulada de certo conjunto de afirmações (formações discursivas). Assim, a análise do discurso de formação do Porto Digital se refere às formações discursivas e aos grupos de afirmações ou a práticas reguladas que permitiram o reconhecimento das demandas daquele cluster.

Nesse sentido, Melo (2004) assevera que o discurso é um conjunto de práticas que estão armazenadas numa memória coletiva, social e institucionalizadas, sinalizando assim que podemos pensar nas várias maneiras de significar um texto, uma vez que os sentidos são múltiplos e se escondem na não transparência da linguagem. Melo (2004) acrescenta ainda que o sentido não está no texto, mas na relação que este mantém com quem a produz, com quem o lê, com outros textos e com outros discursos possíveis.

Para efeitos didáticos, a análise do discurso pode ser dividida em duas amplas linhas que, embora apresentem diferenças metodológicas e teóricas, surgem ambas da necessidade imposta pela linguística de definir uma nova unidade de análise que ultrapassasse os limites da frase: o texto. Na linha anglo-saxão, ao 
contrário do que ocorre na corrente europeia, a análise do discurso não é afetada pela dicotomia saussuriana língua e fala e constitui, assim, uma mera extrapolação da gramática. A linha europeia da análise do discurso segue a tradição, mais especificamente francesa, de atrelar uma perspectiva histórica ao estudo reflexivo dos textos (MAINGUENEAU, 1993). Alias a análise do discurso em sua vertente francesa é conhecida como AD e desenvolveu-se a partir da perspectiva de Michel Pêcheux.

$\mathrm{Na}$ fase da analise do discurso é proveitoso pensar que ela tem 4 temas principais segundo Gill (2002): uma preocupação com o discurso em si mesmo, uma visão da linguagem como construtiva e construída, uma ênfase no discurso como uma forma de ação, e uma convicção na organização retórica do discurso. Não é fácil fazer um receituário para que se possa acompanhar metodicamente, sempre indefinível ela nunca pode ser captada por descrições de esquemas de codificação, hipóteses e esquemas analíticos (GILL, 2002). A esse respeito Fairclough (2001) diz que as pessoas abordam-na de diferentes maneiras, de acordo com a natureza especifica do projeto e conforme suas respectivas visões do discurso.

Como não existe um procedimento fixo para se fazer a análise de discurso, uma vez que esta depende da natureza do problema de pesquisa e da perspectiva/visão de discurso que o pesquisador adota, acabou realizando pesquisas em documentos oficiais do Porto Digital extraídos do seu portal institucional, notas de palestras assistidas e por meio de 02 entrevistas com alguns atores chaves do Porto Digital que são representativos desse cenário. Os entrevistados foram Francisco Saboya (Presidente do Porto Digital) (entrevistado 01) e José Antônio Bertotti (atual Secretário Executivo de Ciência e Tecnologia do Estado de Pernambuco e ex-Secretário de Ciência, Tecnologia e Desenvolvimento Econômico da Cidade do Recife entre 2008-2012) (entrevistado 02).

Durante a fase de formulação e implementação do Porto Digital foram atores chaves para dar voz as demandas específicas desse cluster de TI. Nesse sentido suas falas podem ser enquadrado no âmbito de um esforço conjunto desses sujeitos para legitimar essas demandas junto ao governo do estado, universidade e a 
sociedade civil de forma a consiebtiza-los da relevância desse empreendimento. O NGPD tinha a necessidade de estabeler alianças político-econômicas estratégicas com esse atores chaves e, nesse contexto, surgem vários discursos e contradiscursos, organizados retoricamente, para justificar - ou mostrar falsas justificativas - em relação a esse cluster.

A analise dessa conjuntura socio-política na qual o discurso foi produzido é extremamente importante uma vez que permite captar os vários discursos implícitos nesse processo e que, portanto, sem referência ao contexto não podem ser decifrados. Por outro lado, evidencia a intencionalidade/motivação do discurso.

As categorias usadas para codificação consistem, basicamente, em identificar e examinar as ocasiões em que posições e identidades são construídas acreditamos que a organização retórica do discurso visa levar as pessoas e assumir posições e identidades; e, como as justificativas para para a implementação desse Cluster são representados discursivamente. O discurso tem uma função de representação na medida em que apresenta versões particulares de uma determinada realidade. Ao mesmo tempo contribui para a construção dessa mesma realidade, isto é, para a constituição de modos sociais de ser.

Por fim, não há como escapar do fato de que a análise de discurso é uma arte habilidosa, que pode ser difícil, e exige sempre muito trabalho. Mesmo quando um analista de discurso discute o contexto, ele também está produzindo uma versão, construindo o contexto como um objeto (Gill, 2002). Em outras palavras, a fala dos analistas de discurso não é menos construída, circunstanciada e orientada à ação que qualquer outra. $O$ que os analistas de discurso fazem é produzir leituras de textos e contextos que estão garantidas por uma atenção cuidadosa aos detalhes, e que emprestam coerência ao discurso em estudo. 


\section{O PORTO DIGITAL REPRESENTANDO O DESENVOLVIMENTO DE PERNAMBUCO}

Figura 2: O Porto Digital

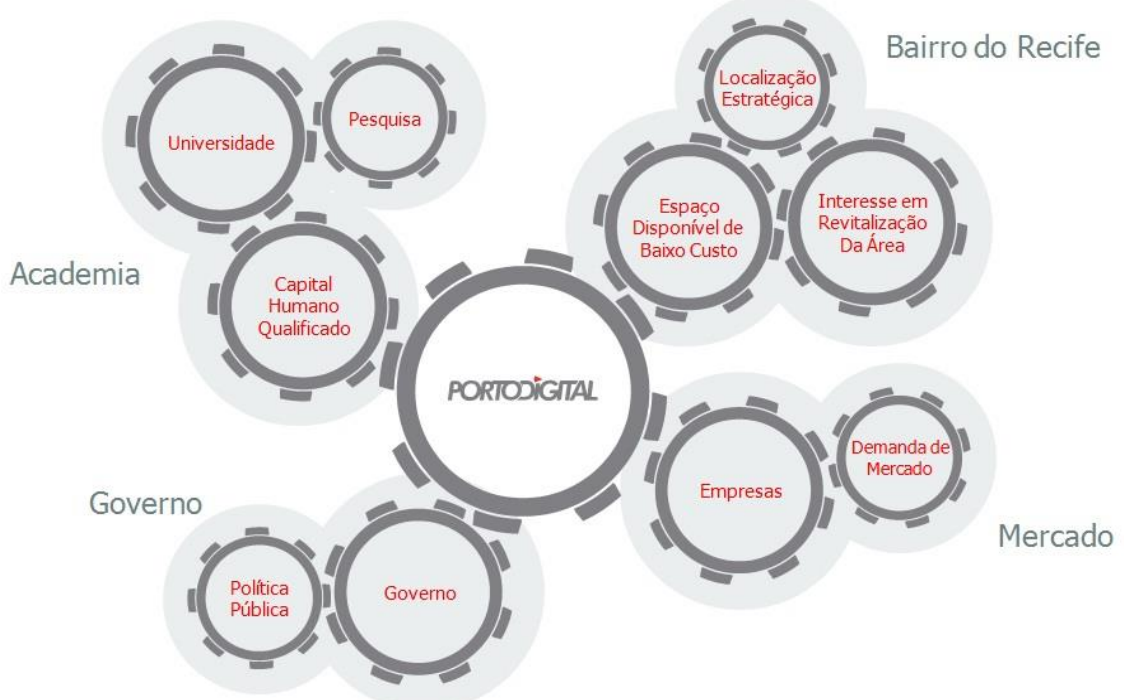

Fonte: Porto Digital, 2012.

Em treze anos de atuação, o Porto Digital se consolidou como um dos principais clusters de tecnologia do País, destacando-se os investimentos proporcionados na melhoria dos processos de desenvolvimento de software, que propiciam a instalação de dezenas de empresas do setor de TIC (PORTO DIGITAL, 2010).

Atualmente, o cluster de TIC pernambucano possui 230 empresas, nesses dados estão inseridas as empresas de softwares e serviços de TIC, empresas incubadas, empresas de economia criativa e as empresas que prestam serviços às empresas de TIC. O cluster é composto, em sua maioria, por pequenas e médias empresas. Porém, empreendimentos multinacionais como a Motorola, IBM, Samsung e Microsoft também estão presentes no polo. (PORTO DIGITAL, 2010; 2012). 
O Porto Digital surgiu da articulação de caráter empreendedor de vários atores, entre eles: o governo do Estado de Pernambuco, o Centro de Estudos e Sistemas Avançados do Recife - C.E.S.A.R -, o Centro de Informática da Universidade Federal de Pernambuco - Cln, e outros órgãos e empresas privadas do setor de tecnologia da região visando o desenvolvimento econômico e social do Estado de Pernambuco e tendo como ferramenta o setor da Tecnologia da Informação e Comunicação (TIC). (PAIVA JR, F. G. et al., 2006, p. 8). (figura 02)

Do ponto de vista econômico do Estado de Pernambuco, conforme o entrevistado 01, o Porto Digital busca:

dar uma contribuição para mudar esse quadro é uma preocupação que a gente tem. Isso está no DNA do Porto Digital. Dar uma contribuição para a reconfiguração da nossa economia. Eu falei, mas lá no Porto Digital têm 230 empresas, onde trabalham 7 mil pessoas, o faturamento das empresas ali do Porto Digital em 2012 foi de 1 bilhão de reais. Estou falando em grande número, não de pequeno número.

A gestão do APL cabe ao Núcleo de Gestão do Porto Digital - NGPD -, que recuperou edifícios para instalar as principais âncoras que trabalham em parceria. Seus objetivos, além da administração do parque tecnológico, é atrair investimentos e negócios. Além disso, atua no sentido de criar mercados para o desenvolvimento de pesquisas tecnológicas; promover a aproximação entre o meio acadêmico e o meio empresarial; apoiar e incentivar o desenvolvimento de novos produtos (bens materiais e serviços) e processos (organizacionais e de tecnologia relevantes para o desenvolvimento sustentável do Estado); gerar empregos, aumentar a arrecadação do Estado (desenvolvimento econômico e melhoria da qualidade de vida); e fornecer infraestrutura física e tecnológica para o crescimento do Porto (PORTO DIGITAL, 2012).

O parque tecnológico também revitaliza esferas não tangíveis tal como o espírito empreendedor que esmoreceu com o tempo no Recife e fomentou o empreendedorismo com a inclusão de empresas de fato locais e empreendimentos 
satélites, fora isso com a instituição da economia criativa foi dado maior dinamismo inovacional ao segmento, comprovando o potencial de geração de negócios.

A maioria dos empreendimentos no Porto Digital nasceu de projetos despontados de Universidades pernambucanas. Resultando na implantação de políticas públicas em parceria com a iniciativa privada, Universidades e órgãos de fomento. Estes projetos e empreendimentos gerados no Porto Digital já lhe renderam 95 prêmios e reconhecimentos, além de 79 projetos ligados a inovação aprovados.

\subsection{As Representações do Porto Digital}

A escolha do objeto de estudo iniciou-se a partir das indagações provocadas na disciplina de Pensamento Contemporâneo em Marketing, do Programa de PósGraduação em Administração da Universidade Federal de Pernambuco (PROPAD/UFPE). Além disso, ocorreram participações nas palestras do evento "Fale UFPE" e do Curso de "Economia Criativa e suas potencialidades", onde Francisco Saboya - Presidente do Porto Digital ministrou as palestras. Ambos os eventos foram devidamente registrados em áudio, e contou-se com o acesso as apresentações em PowerPoint ao seu término.

Em ambas as palestras, o Porto Digital é colocado como o porta-voz de uma nova elite econômica emergente do Estado de Pernambuco e capaz de estimular o desenvolvimento local, diferentemente da liderança socioeconômica tradicional do Estado, a sucroalcooleira.

Especialmente em se tratando da identidade do Porto Digital e o seu papel em relação à representação do desenvolvimento do Estado:

O Porto Digital não é um ator secundário, é sim, um ator relevante para o desenvolvimento do Estado de Pernambuco (entrevistado 01).

Na verdade, a gente está falando do desenvolvimento da economia da informação. É a nova economia e o mundo está querendo aprender com ela. É uma economia do intangível, um negócio que 


\section{Revista das Faculdades Integradas Vianna Júnior}

\section{VIANNA SAPIENS}

edição especial

Juiz de Fora - 2014

está tomando o seu espaço. E vem, ao longo do tempo tomando o seu espaço, porque está associada a uma revolução tecnológica. Tem uma série de coisas aí por trás. Então, quando a gente está falando de Porto Digital, na verdade a gente está falando de uma política pública para o desenvolvimento da economia, que é a economia digital do Estado de Pernambuco. Não é a economia industrial, tradicional, não é a TIB, não é a Tecnologia Industrial Básica, é a economia da informação, é uma economia que está na dianteira, uma economia na qual o mundo está de olho, que está fazendo com que a coisa aconteça. Então, o Porto Digital é, sob o ponto de vista do Governo, um elemento de perpetração numa política pública para o desenvolvimento dessa economia. (CORRÊA, 2007).

O entrevistado 02, acrescenta, descrevendo o cluster como sendo um "modelo exitoso de habitats de inovação no Brasil".

Figura 3: Estratégia do Porto Digital

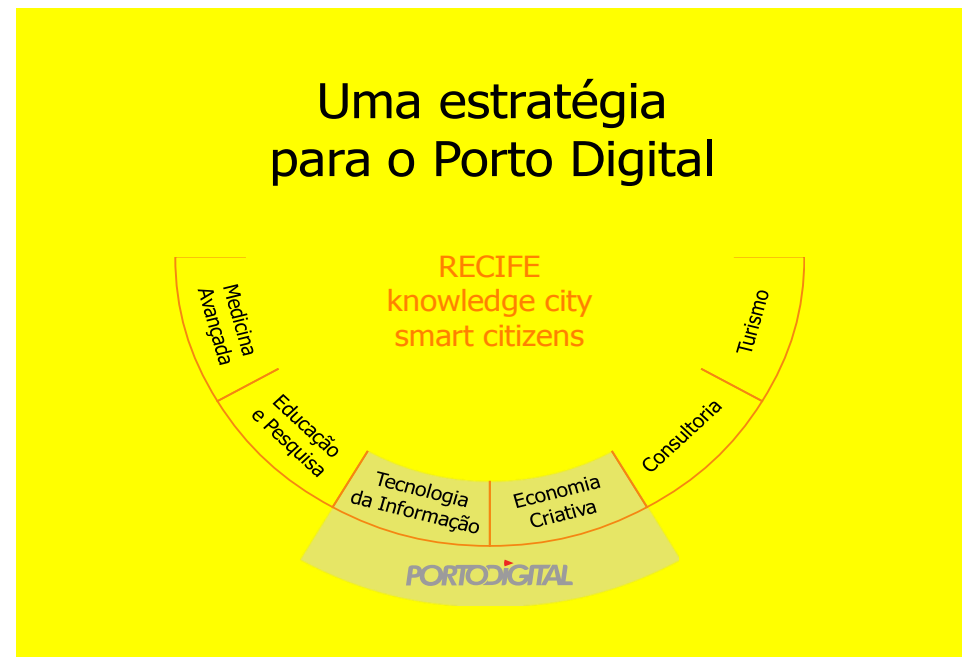

Fonte: Curso de Economia Criativa, $2013 .^{8}$

Outro aspecto destacado é o processo de ressignificação que o Porto Digital vem passando, pois, pode-se perceber na figura que o Porto passa a abarcar além do setor de Tecnologia de Informação, passa a também responder pelo setor de Economia Criativa (EC), por meio da criação do Porto Mídia (PORTO DIGITAL,

\footnotetext{
${ }^{8}$ Figura extraída dos Slides da apresentação de Francisco Saboya no Curso de Economia Criativa e suas potencialidades, realizado na UFPE, em março de 2013.
} 


\section{Revista das Faculdades Integradas Vianna Júnior}

\section{VIANNA SAPIENS}

edição especial

Juiz de Fora - 2014

2012), comprovando assim o que Hall (1999) afirma, que a identidade nunca está completa, é algo sempre em processo.

A informática aqui no Estado de Pernambuco, e particularmente aqui em Recife, até por conta do que significa o Recife para o Nordeste, centro de desenvolvimento, de distribuição, sempre foi a capital cultural, tem muita história, tem muita coisa que acontece sobre o entorno do Recife, no entorno do Estado de Pernambuco, o seu desenvolvimento, a sua interferência na economia, na educação, na saúde, na implementação das inovações, na indústria, no comércio, na moda... bom... sempre foi uma presença muito marcante (CORRÊA, 2007).

Em relação ao patrimônio, o que se percebeu foi que no final da década de 60 e começo da década de 70, surgiu com bastante intensidade, um movimento de organizações em torno da utilização da informática.

Quadro 1: Trechos sobre a narrativa da nação/Pernambucanidade

\begin{tabular}{ll}
\hline Trecho & Descrição \\
\hline 1.3 & $\begin{array}{l}\text { Dessa cidade histórica, cenário da segunda invasão holandesa em 1630, escoou } \\
\text { a maior produção de açúcar do Brasil colonial, tornando-a por séculos uma das } \\
\text { cidades mais modernas e importantes do País. }\end{array}$ \\
\hline 1.4 & $\begin{array}{l}\text { Dos engenhos de açúcar para uma economia baseada em serviços e com uma } \\
\text { participação crescente do setor de TIC no PIB pernambucano. }\end{array}$ \\
\hline 1.5 & $\begin{array}{l}\text { Territorialmente, o Porto Digital está situado no sítio histórico do Bairro do } \\
\text { Recife, acrescentando ao projeto o componente de revitalização urbana. }\end{array}$ \\
\hline 1.6 & Ruínas da antiga cidade e cabos de fibra ótica. \\
\hline 1.7 & $\begin{array}{l}\text { O Bairro do Recife resume no seu perímetro mais de quatro séculos de } \\
\text { formação de uma cidade, nas palavras do arquiteto Sérgio Noé. }\end{array}$ \\
\hline
\end{tabular}

Fonte: Corrêa, 2007.

Por fim, observa-se outro recurso, que caracteriza essa representação do desenvolvimento do Estado de Pernambuco promovido pelo Porto Digital, está imbricada ao que Hall (1999) classifica como participação na construção das identidades nacionais, e no caso do estudo, estendeu-se para o sentimento da Pernambucanidade, que diz respeito à ênfase nas características intrínsecas que formam a cultura de um povo, como seu espírito guerreiro, sua inclinação para o comércio ou qualquer outra apontada como intrínseca a ele. 


\section{CONSIDERAÇÕES FINAIS}

Os sistemas de Arranjos Produtivos Locais vêm se estabelecendo em vários estados brasileiros por meio de estratégias que visam o desenvolvimento econômico e social (PORTO DIGITAL, 2012). A inovação e a mudança que os APLs possibilitam, são características imprescindíveis para o mercado e, desta forma, a capacitação científica e tecnológica, inclusive da melhoria de bens e serviços se transformaram em pré-requisitos para o sucesso de muitos empreendimentos.

Outros condicionantes importantes para o sucesso de um Arranjo são: competitividade, entrelaçamento das empresas (cooperação), entrelaçamento entre empresas e instituições de suporte e ação conjunta do Estado e de outros atores para o aperfeiçoamento do tecido institucional local (PORTO DIGITAL, 2012).

No caso do Porto Digital, percebemos ao longo do estudo que o cluster pernambucano influencia sim na dinamização da economia do Estado, porque criou uma nova alternativa econômica, que possibilita a geração de produtos com forte valor tecnológico agregado, além de ser considerado um campo de excelência, que propicia a permanência dos talentos produzidos pelas universidades e centros de pesquisas.

No entanto, ainda restam divergências quanto ao volume dessa representação, das condições de relacionamento do cluster com a Universidade, com o setor público, com as empresas são fatores que ainda dificultam a consolidação dessa representação.

Por isso, o compartilhamento de ideias, a amplificação da comunicação por meio das pesquisas nas áreas de fomento do Porto Digital, ou seja, as áreas de Tecnologias da Informação e Comunicação (TIC) e de Economia Criativa (EC) poderão corroborar para a superação dessas divergências.

Outro aspecto que vale salientar é a ressignificação que o Porto Digital passa, pois, a sua identidade vem se modelando conforme o surgimento de novas alternativas para o negócio, a exemplo da sua expansão para o Bairro de Santo Amaro, no Recife, onde funcionará o Porto Mídia - Centro de Empreendedorismo e 


\title{
VIANNA

Tecnologia da Economia Criativa do Porto Digital, ou seja, o APL passará a contar com outras áreas, além das suas áreas mais tradicionais de $\mathrm{TI}$, o que caracteriza implicações relevantes para estudos futuros.

\section{THE INFLUENCE OF PORTO DIGITAL REPRESENTATION OF THE DEVELOPMENT OF PERNAMBUCO}

\begin{abstract}
This study aims to understand the influence of Local Productive Arrangement of Information and Communication Technology (ICT APL), called Digital Port, located in the metropolitan city of Recife, in representation of the development of the state of Pernambuco. Qualitative research, through analysis of data obtained through archival research and conducting semi-structured interviews were conducted. The results show that the representation of Porto Digital in relation to the development of Pernambuco, is established through identity, heritage and Pernambucanidade. This enables the generation of new alternatives in relation to the productive chains of the State as well as the permanence of the talents and the expansion of research centers and universities.
\end{abstract}

KEYWORDS: REPRESENTATION. CIRCUIT OF CULTURE. LOCAL PRODUCTIVE ARRANGEMENT. PORTO DIGITAL. 


\section{REFERÊNCIAS}

ALBAGLI, Sarita. e MACIEL, Maria, L. Capital social e empreendedorismo local, Rede de Pesquisa em Sistemas Produtivos e Inovativos Locais, UFRG, 2005.

BERBEL, A. C. A. O processo de internacionalização de um cluster de empresas de software: o caso do Porto Digital. Dissertação (Mestrado em Administração). Rio de Janeiro: Universidade Federal do Rio de Janeiro, Instituto COPPEAD de Administração, 2008.

CASTELLS, Manuel. A sociedade em rede: A era da informação: economia, sociedade e cultura. Vol. 1. São Paulo: Paz e Terra, 2007.

CASSIOLATO, J.; LASTRES, H. O foco em arranjos produtivos e inovativos locais de micro e pequenas empresas. In: LASTRES, H. M. M. et al. Pequena empresa: cooperação e desenvolvimento local. Rio de janeiro: Relume Dumará, 2003. P. 1-10.

CLEGG, S. R.; HARDY, C. Introdução: organização e estudos organizacionais. In CLEGG, S. R.; HARDY, C.; NORD, W. R. (orgs. ed. inglesa) e CALDAS, M.; FACHIN, R.; FISCHER, T. (orgs. ed. brasileira). Handbook de estudos organizacionais, v.1. São Paulo: Atlas, 1999.

CORRÊA, MARIA IRAÊ de SOUZA, Os novos tempos e a constituição discursiva do sujeito coletivo: um estudo no campo de empreendedorismo no setor de tecnologia da informação e comunicação, Dissertação de mestrado Programa de PósGraduação em Administração da Universidade Federal de Pernambuco, 2007.

CORIAT, B. La régulation dans la crise actuelle. Les Cahiers Français, n. 209, p. 65-68, jan./fev. 1983.

DU GAY, Paul et al. Doing cultural studies: the story of the Sony walkman. London Publications, Ltd, 1997a.

FAIRCLOUGH, NORMAN. Discurso e mudança social. Brasília Un B. Cap. 8 pp. $275-293$.

FOUCAULT, MICHEL. Arqueologia do saber. Rio de Janeiro: Forense Universitária, 1997.

GILL, ROSALIND. A análise de discurso. In: BAUER, M. W. e GASKELL, G. Pesquisa qualitativa com texto imagem e som: um manual prático. Petrópolis, Vozes. Pp. $244-270,2002$. 


\section{Revista das Faculdades Integradas Vianna Júnior}

\section{VIANNA SAPIENS}

edição especial

Juiz de Fora - 2014

HALL, Stuart. (1989). 'Cultural Identity and Cinematic Representation' in Framework 36: 68-81.

. (1997) "The Spectacle of the 'Other', in Stuart Hall (Ed.)

Representation. Cultural representation and cultural signifying practices. London:

Sage and The Open University, pp. 223-279.

. "The work of representation". In: HALL, Stuart (org.) Representation.

Cultural representation and cultural signifying practices. London/Thousand

Oaks/New Delhi: Sage/Open University, 1999.

HARVEY, David. A condição pós-moderna: uma pesquisa sobre as origens da mudança cultural, Edições Loyola, São Paulo, 2012.

JOHANNESSEN, J. A.; OLSEN, B. The future of value creation and innovations:

Aspects of a theory of value reation and innovation in a global knowledge economy;

International Journal of Information Management, p. 502-511, 2010.

JULIEN, P-A. Empreendedorismo regional e economia do conhecimento. São Paulo: Saraiva, 2010.

KIRSCHBAUM, C. Indústrias Criativas no Brasil / coordenadores Charles Kirschbaum ... [et al.] - São Paulo: Atlas, 2009.

KUMAR, KRISHAN, Da sociedade pós-industrial à pós-moderna: novas teorias sobre o mundo contemporâneo, Rio de Janeiro: Jorge Zahar, 1997.

LEE, M. J. Consumer Culture Reborn: Cultural Politics of Consumption. New York: Routledge, 1993.

MANGUENEAU, DOMINIC. Novas tendências em analise do discurso. Campinas, Pontes, pp. 9-25, 1993.

MARSHALL, A. Princípios de economia. São Paulo: Sintesis, 2006.

McCRONE, D. et al. (1995). Scotland - the Band: The Making of Scottish Heritage, Edinburgh: University Press.

MELO, F. F., Ironia e Humor na não transparência. In: LUCENA, I. T. et all, Analise do discurso: das movencias de sentido as nuanças do (re) dizer. João Pessoa, Idéia, pp. 151-164, 2004.

NORONHA, E.G.; TURCHI, L. (2005). Política industrial e ambiente institucional na análise de Arranjo produtivo Local. Brasília: IPEA. Texto para discussão n¹076, 31

p. Disponível em < 
http://www.ipea.gov.br/portal/images/stories/PDFs/TDs/td_1076.pdf>. Acesso em 23 Fev. 2013.

PAIVA JR, F. G.; CORRÊA, M. I. S.; SOUZA, A. C. R. A identidade cultural e a articulação de caráter empreendedor na busca por um desenvolvimento local. Anais da Enanpad; Salvador, 2006.

PIMENTEL, T. D.; CARRIERI, A. P. E CABRAL, C.A. O discurso e sua análise no enfoque Foucaultiano da formação discursiva: um método de pesquisa nos estudos organizacionais. Gestão.Org, Revista Eletrônica de Gestão Organizacional. Vol. 3, n. 2, mai/ago. 2005.

PORTO DIGITAL. Perspectivas para os Setores de TIC e Economia Criativa com a Expansão do Porto Digital para Santo Amaro. Apresentação Porto Desembarque. Recife: Porto Digital, 2012. Perfil Geral do Porto Digital. Recife: Porto Digital, 2010.

RAVASI, D.; RINDOVA, V. Symbolic Value Creation. The Sage Handbook of new approaches in management. 2.6: 270-284, 2008.

RAVASI, D.; LOJACOMO, G. Managing Design and Designers for Strategic Renewal. Long Range Planning. 2005, 38: 51-77.

SENNETT, RICHARD, A corrosão do caráter: as conseqüências pessoais do trabalho no novo capitalismo, Record, Rio de Janeiro, 1999.

SMITH, C. De la automatización de los años sesenta a la especialización flelxible: un déjàvu de las panaceas tecnológicas. In POLLERT, A. (org.). Adios a la Flexibilidad? Madrid, MTSS, pp.225-252, 1994.

TAYLOR, F. W (1856-1915). Princípios da Administração Científica / Frederick Winslow Taylor; Tradução de Arlindo Vieira Ramos. 8ª edição. São Paulo: Atlas, 1995.

YÚDICE, G. A conveniência da cultura: usos da cultura na era global. Belo Horizonte: Editora UFMG, 2006. 